tributes a study of the connexion between age and severity of disease in small-pox; 1,884 unvaccinated cases of this disease are classified according to the type and geverity of the eruption, and the conclusion is reached on this basis that small-pox (irrespective of the disturbing influence of vaccinstion) among children under 10 has a tendency to be of a mild type, whereas small-pox over ro years of age tends to assume a severer type. Dr. Turner himself shows, however, in a subsequent table that "if we judge the severity of diseace from the death-rate we get quite a different result." Parenthetically we may mention that throughout this report the word " death rate" is employed when case-mortality-that is, fatality-is indicated. It would conduce to lucidity if these words were employed in a differentiated manner. Returning to Dr. Turner's paper, it is difficalt to understand how small-pox can be less severe among children under 5 , and yet the fatality among such children is higher than at most other periods of life. We should be better satisfied that the higher fatality of small-pox among children under 5 is " due to the low vitality of young children" if this higher fatality were found to be confined to the first year of life.

Dr. Goodall has a very important note bearing on the origin of "return cases" of scarlet fever." In this note he shows that of 1,000 consecutive cases of scarlet fever 26.0 per cent. were the subject of some complication on admission, $3 \mathrm{I}$.I per cent. developed complications after admission, though onethird of the latter had one or more complications on admission, others developing later. These figures obviously do not lend any support to the suggestion that the complications of scarlet fever are communicable.

Dr. Caiger has also a note of an interesting comparison between the incidence in the South-Western Hospital of rhinorrhoea and otorrhoea in two wards, into one of which only simple and uncomplicated cases of scarlet fever were admitted, while into the other all cases were admitted withoat selection. So far as rhinorrhoea is concerned, the differences between the two series of cases are so slight that it can be definitely stated that the selection appears to have had no influence. In regard to otorrhoea, the ward for selected cases appears to show some superiority, but the number of cases is too small to enable any positive conclncions to be drawn, and it is highly desirable that the experiment should be continued under rigid conditions as to comparability of cases, especially as to age and sex.

\section{THE DIET OF THE PRECIBICULTURISTS}

By Harry Campbeld, M.D., F.R.C.P.,

Physician, North-West London Hospital and to the Hospital for Diseases of the Nervous System, Welbeck Street. IV.

The Diet of THE CaLIFornians.

The Californian or "digger" Indians inhabit territory in the United States of America between $43^{\circ}$ and $32^{\circ}$ to $30^{\circ}$. Among them we may include the Shoshones who are scattered over Sonth-Eastern Oregon, Southern Idaho, and the whole of Nevada and Utah.

Culture.-These people are fast coming under the influence of the white man and their lands becoming changed by agriculture, mining, and other industries. Until quite recently, however, they were in their original primaitive state, and some of them remain so even to this day. They exhibit a very low phase of culture. They do not, speaking generally, cultivate the soil, and are too lazy to hunt, except in a casnal way, subsisting ehiefly upon the uncultivated kingdam. Religion they havemone. They, in fact, present, though in a somenthat dagraded form, the primitive pre-agricultural phase of and ture as it once existed throughout the entire American continent, and were evidently driven into the region the mow ocangy by more warlike and vigorous tribes. The Northern Californians are greatly superior to the others, the tribes of Central Califionia being the most degenerate. In two industries the Ceatifornians display remarkable skill: they axe expert tannens amd basket makers, their bottles made from closelyplaited grass being marvels of workmanship.

\section{Animal Food.}

Almost every living creature that can be procured is acceptable to the Digger Indian. The coast tribes subsist largely on fish, a mode of subsistence which well suits their indolent temperament; many of the inland tribes come down to the coast in the fishing season, remaining there until the shoals leave. They know little of navigation, but sometimes use canoes and rafts when the sea is smooth. Shell-fish are eagerly sought after, notably muscles and clams, which are considered a great delicacy, and in the diving for which they display great skill. Some of the coast tribes show, indeed, a great fondness for the water. We know from the shell mounds found on the eosst in different parts of the world that shell-fioh entered largely into the dietary of primitive man, and wumeron ancient shell mounds are met with in California. Seals and stranded whales are also eaten, and it is an interesting fact that the natives use the dried whalebone fonnd on the coasts for dyepepsia, donbtless on the same principle as isinglass is employed in our own country as a household remedy for this affection. Fresh-water fish arealso eaten, notably galmon, which in proper season abound in many of the streams, constitnting, indeed, for some tribes a staple article of food; salmon roe is especially esteemed. Hunting ill-suits the lazy disposition of the Californians, who in this respect stand in sharp contrast with the Australians, though some of the mowntain tribes are said to show considerable skill in the chase. Among the animals hanted are: the deer, antelope, elk, monntain sheep, braffalo, coyote, wild cat, beaver, and skunk: rabbits, hares, squirrels, rats, and mice are also eaten. Wild fowl, including the quail, swift, crow, hawk, and owl are obtained in mall qrantities. Reptiles, insects, and vermin seem, however, to be preferred to any of these; for example, lizards, snakes (excepting the rattlesnake), toads, locusts, crickets (mamy of which are large and succulant), grasshoppers, ants, pediculi, earthworms, snails and grubs (such as those found in decayed wood), and chrysalides.

Cannibalism. - The Californians do not appear to bave consumed human flesh as food, but portions of the body of a renowned enemy slain in battle were devoured with the object of acquiring something of the warrior's courage.

Domesticated Animals. - The only domesticated animal is the dog.

Methods of Procuring Animal Food.-Being little given to warfare or hunting the Californians possess few weapons; some tribes are provided with guns; others still use the bow and arrow for small game, the arrows being poisoned with the venom of the rattlesnake or with putrid liver. They display considerable ingenuity in making traps and snares. They capture deer by digging in the trail of these animals some pitfalls some to to 12 ft. by means of fire-hardened sticks, carrying the earth away in baskets. 'In stalking the antelope the hunter fixes on his head the horns of this animal by which means he is able to get close to his quarry; or the creature is surrourded by a circle of horsemen and clubbed to death. Ground squirrels are trapped by means of a noose. Wild-fowl are decoyed and netted. Fish are sxeared, the spears sometimes having movable heads, or caught in nets made of rushes or twigs, or they are procured by poisoning the water containing them, as, for instance, by soap root. Lizards are dragged out of their holes by means of a hooked stick. Ants are obtained by placing upon an ant-hill a piece of bark or fresh hide and brushing off into a bag the swarms as they collect, where they are dried for future use. Grasshoppers are caught in nets, or by being driven into pits, either by firing the surrounding grass, or beating it in gradually-leseening circles.

Methods of Preparing Animal Food.-The Californians do not consume raw animal food to the samo extent as certain tribes on the Atlantie cosst. Fish they not infrequently eat raw, and at best their cooking of animal food is perfunetory. Thus a rabbit is placed upon a fire and is consumed after the mere surface has been charred, a large portion remaining practically raw. Of one tribe we resd "they did not understand dressing food, but were ancustomed to throw their game, fish, birds, snakes, bats, or nats, upon the fire and eat it, entrails and all, charred on one side and dripping with blood on the other." Fish are sometimes broiled in embers, the bones being sometimes first removed. They cook their white flesh in underground owens of mueh the same pattern as those employed by the Australians. The Central Califormians cook the flesth of the stranded whale in holes dug in the ground and eurbed up with stone-like walls; over these they build large fires to heat them thonoughly, clean ont the cosls and ashes, fill them with flesh, cover the opening with sticks, leaves, grass, and earth, and thas cook their repast. They also boil their animal food, especially fish, by dropping hot stones into water contained in vessels made of closelyplaited grasses, or imto artificially made pools of water. Lizards, snakes, grasshoppers, and onts are roasted aliwe on a dish containing hot embers, and are either eaten straightway or 
used to thicken soup. Crickets were formerly roasted in large quantities by firing the woods. Grasshoppers are dried in the sun, and, thus prepared, can be stored for winter use; or they are mashed into a paste, or ground into a fine powder, mixed with mush, or salted, and then baked in underground ovens and eaten like shrimps. Other insects-for example, caterpillars-are also sun-dried, and then ground into powder. Earthworms are employed in making soup.

Storage of Animal Food.-Fish, especially salmon and smelts, are smoked and dried, in which condition the former are stored in large quantities ; meat is also dried. Insects are dried in the sun and stored either whole or ground into powder. Smelts are smoked on low wooden kilns, with interstices to allow the smoke to rise up freely, and then dried in the sun. "An Indian on a journey always has some dried pieces of smelt or rich orange-coloured salmon."

$$
\text { Vegetable Food. }
$$

California is rich in wild vegetable foods suitable for man; Powers mentions seventy-three of them as being used by one tribe alone, this number including those employed medicinally, as well as for food, and there is no doubt that most Californian tribes subsist chiefly on vegetable food. According to Powers, the tribes inhabiting oak forests derive fourfifths of their food from the vegetable kingdom, especially from acorns

Roots.-All sorts of "fleshy roots"areconsumed. As in the case of other vegetable foods they are gathered by the women, who " do all the drudgery." These roots are sometimes grouped together as grass nuts, and mostly belong to the natural order Liliaciae. Among them the cammas, sometimes spoken of as the wild potato, is one of the most important; there are several varieties of it; one-the kais-has a root of about $\mathrm{I}$ in. long and the thickness of the little finger; it is dug up by the women in early June by means of a fire-hardened stick, a single squaw being able to procure half a bushel or more in a day. There can be no doubt that quite a large quantity of starch is provided by these roots, a fact which helps to explain the plumpness of many of the Californians in early youth. Many of the roots are said to be sweet when rossted.

The Smaller Seeds. - Among the smaller seeds are those of the following: A coarse wild grass, a species of yellow blooming, tarry-smelling weed-the olly seeds of which are as "rich as butter"- the crowfoot, a small weed which grows in ravines, the common sand grass of the desert, the bunch grass, wild rice, wild oats, wild wheat and wild rye.

Several methods are adopted for harvesting these small seeds: (I) a large basket is borne on the back, while with a smaller scoop-sheped one, held in the hand, the ripe grass is swept and the seeds thrown into the larger basket; (2) the harvester holds a large, deep, conical basket under the left arm, while a amaller one, held in the right hand, is swept in a semicircle among the ripe seeds and brought round to the larger one into which the contents are discharged at every stroke; (3) the squaw carries in one hand a basket and in the other a kind of wicker-work bat with which she beats the grass heads over the basket; (4) a large-handled basket is repeatedly swept through the seed. These various methods of harvesting the seeds of grasses are of great interest as showing that man long before he began to cultivate the cereals was fully alive to their high nutritive value. Not less remarkable are their elaborate methods of milling and grinding the wild grain they harvest, and of converting the grain thus obtained into bread and cakes.

The Larger Seeds and Nuts.-Among these are the seeds of the suntlower, the pond lily, various pines (for example, the nervada nut pine and joint pine), and cactus (for example, the devil's pin-cushion). The mazanita berry is held in such esteem that it is honoured at the time of its ripening with a special dance. In some regions it grows in great abundance. "I have seen," writes Powers, "thickets of them wherein an acre could be selected which would yield more nutriment to human life than the best acre of wheat ever grown in California after the expenses of cultivation were deducted." Acorns occupy a still more important place in the dietary of the Californians; they and salmon have indeed been called the meal and pork of these people. According to Powers foursevenths of the entire food of the inhabitants of the Californian oak forests consists of acorns, and many old Indians still prefer their acorn meal to the finest wheaten flour. Six different kinds of acorn are used, that of the mountain white oak being the favourite. The acorns are gathered in long conical baskets by the squaws and old men. In these oak districts " the invariable sound that first salutes the ear as one approaches a village is the monotonous thump, thump of the pestles used by the patient women" whlle pounding acorns; and on a sweltering day not a sound is heard but this "eternal thump, thump" (Powers). When acorns are scarce the Indian secures the stores laid up by the woodpecker, though he would deem it sacrilegious to do this unless hard-pushed. The Californians dedicate a special dance-the "all-eating dance"-of a semi-religious character to this important food. It lasts several hours, and at its finish acorn porridge is handed round and liberally partaken of by the entire company assembled.

Liscious Fruits. - Though doubtless several varieties of luscious fruits enter into the dietary of the Californians, the only varieties I am able to mention are the choke-cherry, the astringent, juicy fruit of a species of wild cherry, and the small tomato-like fruit of Lycium Andersonii, in its fresh state "quite palatable." The Indians often dry this fruit and make it into a mash or soup.

Greens.-Of the many kinds of "greens" consumed by the Californians perhaps clover is the most important. When in season it is eaten in large quantities, its early gathering being celebrated by the "clover dance," and at this time a whole village may be seen squatting in a lush clover meadow and snipping off the blossoms with the forefinger. Wild lettuce is another favourite food, and from it the Indians prepare a salad by placing the lettuce leaves over the nests of the large red ant; the insects swarm over the leaves, leaving a trace of formic acid, which takes the place of our own vinegar. Many green vegetables are prepared by boiling-for example, the leaf of the yellow dock, the highly saccharine buds of the yucca, and the leaves and stems of several large crucifere, which, in the unprepared state contain nocuous ingredients. When hard-pushed the Californians will eat almost any kind of green herbage, after suitable preparation.

Flowers.-A sweet flower resembling honeysuckle is sometimes eaten.

Mushrooms.-Some of these are eaten with great relish.

Algae.-The coast tribes include sea-weeds in their dietary. One glutinous variety they press into loaves when wet and subsequently dry in the sun.

Artificial Drinks. - Intoxicating llquors are unknown. In summer they make a drink by soaking mashed mazanita berries in cold water, and imbibe it by means of "the shaggy knob of a deer's tail." They do not appear to chew gum like the Australians, but some tribes chew the twigs of the rabbit bush; men and children are said to munch the kais root all day long. As in the case of other pre-agricultural peoples honey constitutes a staple article of food among the Californians. Most of it is black and bitter.

Storage of Vegetable Food. - The Californians appear to resort to storage of their vegetable food more than any other preagricultural people. Acorns are stored in large quantities. Powers describes how each smoke-blackened hut in a hamlet is surrounded by one or more wicker-work, thatched acorn granaries, placed either on the ground, or mounted some feet above it. As many as a hundred bushels have been found in one wigwam. Roots and geeds are by some of the more northerly tribes stored in large wicker boxes, built in the lower branches of strong wide-spreading trees, the trunks of which are smeared with pitch for protection against vermin. Some tribes cache their winter hordes under rocks and bushes out of sight of their enemies. Large quantities of pine nuts are cached in dry places, and, if properly stored, are said to keep for years. Mesquit pods containing hard seeds are gathered in the autumn and cached until spring. The cammas root, bulbous and onion-shaped, is dried in large quantities every summer and stored for winter. The rootlets of rushes are sun-dried and ground to flour, which is capable of storage. Various grass seeds are also stored after having been similarly sun-dried and ground. The prickly pear is stored either after it has been sun-dried or cooked.

Methods of Preparing Vegetable Foods.

The Californians resort to highly elaborate methods in the preparation of their vegetable food. They know how to remove by maceration and to destroy by heat, bitter or poisonous ingredients, how to hull wild grain, how to dry and grind various vegetable substances, such as roots, acorns and wild cereals, and from the flour thus obtained to make variously-flavoured cakes, puddings and gruel ; and they have moreover elaborate methods of cookery, boiling their food in. watertight baskets, broiling it in embers and steaming it in underground ovens.

Methods of Preparation involving the Removal of Nocuous Ingredients.-Acorns, after being shelled and sun-dried, are put 
into bottomless baskets placed on a flat stone, and pounded by means of long stone pestles into fine flour; the latter is then transferred to a hole dug in porous soil, such as sand, and water poured in and allowed to percolate slowly, the process being repeated until all the bitterness has disappeared trom the mass; sometimes the flour is washed with hot as well as cold water. From the $f$ ur thus prepared bread, often flavoured with berries and herbs, is made; as are also puddings and porridge. Acorn bread is black and has the consistence of cheese. The nocuous ingredients of many green substances are also removed by maceration ; they are put into boiling water for a few minutes, then washed in cold water and squeezed, this process being repeated, if necessary, five or six times, until all the objectional ingredients have been removed. The following are instances of the destruction of nocuous principles by heat: The Shoshones render certain poisonous roots edible by baking them in underground ovens; the poisonous buck-eye, a species of horse-chestnut, is prepared by being roasted underground, and then stone boiled to a pulp ; in times of dearth the soap root (used for poisoning fish) is eaten after undergoing the following preparation: the roots are made into a heap and covered with leaves; over this a fire is made and allowed to burn for several hours until the poison is thoroughly roasted out and the root has become quite sweet and palatahle.

Methods of preparing Vegetable Food not involving the Removal of Nocuous Ingredients - The seeds of grasses, after being parched, are beaten into flour, which, as is the case with the Australians, may be eaten without further preparation, or made into bread, cakes, and mush. The chaff is winnowed from the grains in various ingenious ways; in the case of wild oats the equaw places a quantity of grain in a basket; the grain is then slightly moistened and stirred with a stick; this causes the chaff to accumulate on the surface, when it is burnt off by passing firebrands over it; in the case of sandgrass seeds, the chaff which remains after grinding is winnowed and sifted out. Seeds are also roasted in embers in the following ingenious fashion: Into a basket containing seeds embers are placed, and the basket is swung so as to shake the coals and seed well, and bring them "in continual close contact without burning the seed." The seeds of the joint pine are roasted and ground, and the flour made in to hitter bread: those of the pond lily "form an excellent material for bread or panada," and are collected by some tribes in large quantities. A palatable black bread is made from the flour of small black oily seeds. Sunflower seeds pounded into meal constitute a favourite food. Mazanita berries are pounder with a stone pestle, and the beaten mass placed in small quantities at a time on a round mat, which is incliner in various directions to allow the seeds to roll off. The flour thus obtained is stone boiled in a basket-bottle or sand pool, and yields a panada which is sweet and nourishing, or a thin porridge which is eaten "with the shaggy knob of a deer's tail." The cones of the nervada nut-pine are beaten from the trees in early aulumn, spresd on the ground, and exposed to the sun until the scales dry and crack, thus allowing the seeds, or "nuts," to escape when beaten; the seeds are then roasted. The petah root, after being dried and ground into meal, is eaten raw or made into bread. The dried pods of the mesquit bean are pounded in a wooden mortar, and the flour sifted out and made into small cakes. or loaves. The "prickly pear" (obtained from a species of cactus) is prepared thus : the fleshy joints when fully distended with sweet sap, that is in May or June, are broken off with sticks, and after being divested of their prickles, are sun-dried, when they will keep indefinitely. They are prepared for eating by boiling, and adding salt, or, instead of being dried, they are cooked in underground ovens. A hole, or oven, is dug about a yard in diameter and a foot deep, and lined with stones; over this a fire is kindled. and. other stones thrown in; when the stones are thoroughiy heated, the ashes, and all but a single layer of stones, are removed, and some fresh moistened grass spread in the oven; alternate layers of cactus-joints and stones are now put in until the pile is well rounded. this is covered with sacking, and finally with moist earth. After about twelve hours of steaming the pile is opened, and the nävo, as it is now termed, is eaten with salt, or dried and preserved. Mescal is cooked in a similar way, the ovens in this case being much bigger, and the cooking, which is accompanied by certain ceremonies, occupying two days. In the neighbourbood of the hillsides where the mescal grows numerous ovens, which have been used in previous years, are to be seen. The common reed furnishes what is known as "sugar"; the reeds are cut in early summer, then ground, the finer portions being separated by sifting and constituting a " moist, sticky stuff," which is moulded by the hands into a thick, gum-like mass, and this is roasted till it swells and browns slightly, in which toffg-like state it is eaten.

Starch and Sugar. - As in the case of other pre-agriculturists the Californians are ignorant of the art of extracting starch and sugar from vegetable substances.

$R$ tation of Food. - Their food is greatly influenced by season. Thus, according to Powers, the northern Californians eat in the early part of the year the sweet inner bark of the yellow pine; next the clover comes into season, then throughout the summer various kinds of roots are ready for consumption; next (about June and Jaly) salmon; after this wild oats and grass seeds, then mazsnita berries and pinon nuts, acorns finishing the harvest of the year; while game and vermin of many kinds are eaten at all seasons.

Quantity of Food.-The country of the Californians yields an abundance of food. The rivers at times are said to be black with salmon, which are dried, smoked, and stored in large quantities. Acorns abound in the oak forests, and are as we have seen, copiously stored, while a plentiful supply of other valuable vegetable food-snch as roots and mazinita berries - is available. The country is, indeed, said to afford "every life-sustaining substance, which can be procured with comparatively little trouble," and it is nnusual " that a tribe cannot procure a sufficiency food with comparatively little work." Bancroft writes: "Before the arrival of the miners game was so plentiful that even the lazy natives could supply their necessities," and the rivers "were darkened by the blackbacked myriads." Salmon was once 8o plentiful that an Indian could scarcely thrust his spear down without transfixing one or more ; "and, according to Powers, a party of six Indians speared over 500 salmon in one night, which would, at a moderate calculation, give $500 \mathrm{lb}$. to each spearman. On the other hand there is evidence that food is not always so plentiful, for we read that " after a long winter on short commons they are glad to allay hunger by filling their stomachs with the sweet inner bark of the yellow pine,"and an old blind Californian was once seen cutting up his sandals for a meal. The Californians are capable of consuming enormous quantities of food at a sitting. Bayert says of certain tribes that $24 \mathrm{lb}$. of meat was not considered too much for one person and he mentions the case of a native who ate geventeen melons right off. The same writer refers to the curious custom among some of the natives of attaching a piece of string to a morzel of meat so that they may withdraw the latter after swallowing it. a procedure they repeat as many as a dozen times - "Um den Geschmack davon desto länger zu haben."

Time of Meals. - Whatever be the general custom, in the case of many tribes, at all events, there are no fixed times for meals, food being eaten just when it comes to hand.

General Observations - Of certain tribes it is specifically stated that they do not drink with their meals, and that they eat little or no salt. All food is eaten cold. Some tribes either drink water out of the hand, or stoop down and drink after the manner of cattle. Wild tobacco is smoked, and sometimes a rude attempt is made at cultivating it by scattering tobacco seeds about the camp, and taking care not to disturb the growing plants. They also from time to time burn the meadows to increase their fertility.

Sweat Houses. - The sweat house, or temescal, as the Frunciscan Fathers named it, is a species of Turkish bath in vogue among the Northern Californians, and is regarded as a panaces for every kind of malady. It consists of a hole dug generally by the side of a stream, and roofed over so as to make it almost air tight. Ingress and egress are effected by a small hatchway which is instantly closed upon entering or leaving the chamber. In the early autumn a fire is kindled in the centre and kept alive till the following spring. The bathers gquat inside and there remain, in spite of the close, smoke-laden atmosphere, until they break out into a profuse perspiration, when they leave the chamber and plunge into the neighbouring stream. The Central Californians also employ another method of promoting perspiration : a hole, just large enough to receive one person, is dug in the sand, and over it a fire is kept buraing until the sand is thoroughly heated; the fire then is removed and the patient laid in the hole, and covered as far as his head with sand; when profuse sweating has been induced he is taken out and plunged into cold water.

BIBLIO if APAY.-CALIY ORIIAN IN DIANS

T. J. Farnham, Travtls in the Great Wotern $P$ airier, the Anahuac and 
under the Command of Captain Lewis and Clarke to the Sources of the Missouri and Rocky Mountains, 1845 . Hubert Howe Bancroft, The Native Races of the Pactfic States of North America, 1875.6. S. Powers, Tribes of California, vol. iit., 1877. F. V. Coville, Contributions for U.S. National Herbarium, The American Anthropologist, vol. v, 1892 .

\section{PREVENTION OF CONBUMPTION.}

The Sanatoriom Movfment in america. IN American Medicine of June 17 th, Dr. William H. Baldwin gives an account of the progress of the sanatorium movement in America. The Channing Home, founded in Boston in 1857 , the Oullis Consumptives Home in 1864, and the House of Rest in New York in 1869, were not sanatoriums in the modern sense of the word; they were intended to receive patients who would probably remain until removed by death. Even earlier than these were the Lincoln Home, started in New York in 1839 , and the House of the Good Samaritan in Boston in 1861 , but they were not meant for consumptives more than for other patients believed to be incurable. Next came the two institutions of the Protestant Episcopal Mission in Philadelphia in 1876, intended especially for consumptives, which took patients in all stages, and treated them. During its existence that organization has cared for more than 3,500 patients. Five years later, in 188r, the Brooklyn Home for Consumptives was founded ; it was intended, as its name implies, to shelter those prevented by the disease from caring for themselves or being received elsewhere. St. Joseph's Hospital, in New York City, for poor consumptives was started with the same object by the sisters of the Poor of St. Francis in 1882. It is impossible to discover in the purpose or conduct of any institution up to that time any ray of hope for the consumptive, any expectation of successful treatment.

The Pionerer of the Movement in America.

The first real advance in the sanatorium movement in America was made by Dr. Trudeau in Saranac twenty years ago. If Koch's discovery was the revelation of a new dispensation, Dr. Trudeau may be considered as the first preacher of the new gospel of "open air" in America. Interest in the subject on the part of those studying the treatment of the disease developed rapidly, and as they came to similar conclusions, and living witnesses from various localities proved the efficacy of the new treatment, other sanatoriums were established, until there are now 135 institutions of various kinds, new and old, in 33 States and provinces in the United States and Canada where tuberculous patients are cared for; one-third of these are in New York and Pennsylvania. Collectively they provide accommodation for $8,4 \mathrm{co}$ patients, of which 30 per cent. are in New York State alone. Of these sanatoriums 14 were established in 1902, 24 in 1903, and 21 in 1904, making as many in the last three years as in the seventeen which preceded. The rapid acceleration of the movement, after Dr. Trudeau's beginning, warrants the hope of corresponding future progress.

State Sanatoridms.

The first institution of the kind established by a State or provincial association was the Muskoka Cottage Sanatorium at Gravenhurst, Ont., in 1897, by the National Sanatorium Association, with a capacity of 75 . The results were so favourable that another of similar size for people unable to pay was started five years later in the same place. The latter is supported in part by a subsidy of 1.50 dols. per week for each patient from the provincial government, and is therefore quasi-provincial. Resembling this in its relations with the State is the Maine Sanatorium recently established by the State association. This has received aid from the state, though it is not under State control, and in a way it takes the place of a State sanatorium. The first State sanatorium was established by Massachusetts at Rutland, fifty miles from Boston, in 1898 . This is a large institution for early cases which had last year an average of 257 patients, and has been in every way successful, 73 per cent. of the incipient cases, in those discharged in the last few years, having been arrested or the patient apparently cured. Patients are required to pay 4 dols. per week, the State making up the remainder of the cost, which last year was 9.36 dols. per week. The next State sanatorium opened was that of New York at Ray Brook in the Adirondacks on Jaly 1st, 1904, for incipient cases, with a capacity for 120 . The results 80 far have been excellent. Admission is granted in the order of applications, with preference to those who are unable to pay, and who, after being recommended by local authorities who assume the charges up to 5 dols. per week, are examined by local physicians appointed for the purpose.

The erection of State sanatoriums has been begun in Rhode Island, New Jersey, Minnesota, Ohio, New Hampshire, Missouri, and Michigan. The Tuberculosis Commission, appointed by the $L$ gislature of 1903 to investigate conditions in Wisconsin, has just made its report, setting forth very clearly the advantages of a State sanatorium. A Bill has been presented to the Legislature now in session asking for 90,000 dols. for the erection of buildings and 25,000 dols. as annual maintenance for them. It has been approved by the Committee on appropriations, and, as the sentiment in the Legislature is atrongly in favour of the movement, it will undoubtedly be passed, and a start made this year. It may be said, therefore, that in eleven States and one province State sanatoriums are erected or their establishment assured.

In several other States the question is under serious consideration. Connecticut lus no state sanatorium, but gave 25 ,00 dollars towards the equipment of Gaylord Farm Sanatorium, which cost about 100,000 dollars, the remainder being raised by private subscription, and has given 5,000 dollars a year toward its support for two years. In the District of Columbia, the request made at each of the last two session for an appropriation to start a sanatorium, was rejected. In accordance with a resolution passed by the Indian Legislature, a commission to investigate and report to the next Legislature as to a State sanatorium, has just been appointed, with the secretary of the State association as medical member. In Kansas, a resolution asking for the appointment of a tuberculosis commission to investigate the desirability and cost of erfeting a State sanatorium, passed the House, but failed in the Senate. The commission appointed in Maryland, in 1902, to investigate the general facts in relation to tuberculosis in the State, was reappointed last autumn to continue its study, and also to report in 1906 as to the "construction, cost, equipment, maintenance and location of sanatorium for the treatment of tuberculosis." A bill appointing a commission consisting of two physicians and the commissioner of forestry to build two State sanatoriums in Pennsylvania, and making an initial appropriation of 300,000 dollars therefor, was recently vetoed by Governor Pennypacker, not because of any objection to such institutions for the State, but because the Bill was loosely drawn and opened the way for abuses. In Washington, a Bill making provisions for a site and for preparing plans for the erection of a State sanatorium, was introduced in the last Legislature, but was crowded out in the closing days of the session. There was no opposition. In Kentacky a Committee has been appointed to bring the matter hefore the Legislature; which meets next year. In South Dakota it is intended to bring the matter to Congress at its next session, but no steps have been taken toward a State sanatorium. In Texas the subject was brought before the Legis]ature, which has just adjourned, but nothing was done. In Virginia, West Virginia and Montana also, Bills introduced several years since failed, and no efforts are being made at present. The recent California Legislature pased a Bill appropriating 150,0co for a State eanatorium, put the Gover vetoed it. In Arkansas, Arizona, Georgia, Idaho, Mississippi, Nevada, New Mexico, North Carolina, North Dakota and Oregon, report that nothing is being done for a State sanatorium, and failure to furnish any information indicates that nothing has been accomplished in the remaining States.

Sanatoriums for Sailors and Soldiers.

In 1898 Surgeon. General Wyman took up the question of a In torium for tuberculous seamen, and after various locations had been investigated the old military reservation at Fort Stanton, New Mexico, was turned over to the Marine Hospital Service in 1899 for the purpose. The reservation contains 38 square miles, most of it under fence, and the accommodations can be indefinitely extended by adding tents. The nu has not yet established a sanatorium, but since December, 1903 , has been experimenting with a camp at the naval hospital at Pensacola. Florida, accommodating 50 in tents, and has 8 c fficers and 64 enlisted men in the army sanatorium at Fort Bayard. The results have been most favourable, leading to studies of sites and plans for a naval sanatorium. The results have be en excellent. In 1899, also, Sargeon.General Sternberg established a United States general hospital for tuberculons soldiers of the United States army at Fort Bayard, in New Mexico. The results have been very favourable. There were at the end cf last year about 250 under treatment. 